\title{
Towards a cognitive-sociological theory of
}

\section{subjectivity and habitus formation in neoliberal societies}

\begin{abstract}
Disconcerting findings from sociological research suggest that Western youth are developing subjectivities that reflect neoliberal discursive formations of self-interestedness, competitiveness, and materialism. However, propositions about 1) the cognitive-affective mechanisms that explain how youth acquire and reproduce neoliberal ideology, or 2) the dispositions and behaviours that typify a neoliberal subject, remain vague. Therefore, in this article I provide a novel conceptualisation of these two psychosocial facets that can help advance understandings and investigations of the emerging modes and societal consequences of neoliberal subjectification. Specifically, I review major theoretical tenets from the respective literatures on neurocognitive development, social cognition, neoliberalism, and neoliberal hegemony. I then synthesise these tenets within a modified habitus formulation to sketch a testable cognitive-sociological model for explaining and exploring some of the distinct dispositional values, attitudes, and practices that youth raised in societies with institutionally and culturally prevalent neoliberal norms and discourses may potentially develop and enact.
\end{abstract}


The past three decades of neoliberal policy inputs and outputs have, to differing but considerable extents, transformed many Western countries' major media, educational, cultural, and recreational institutions into market and ideological apparatuses (Hall and Rustin, 2015; McGuigan, 2010; Slater, 2015; Sloan, 2008). As a result of this ongoing structural reconfiguration, successive millennial generations (i.e., post-1980 birth cohorts), and particularly those in the USA and the UK, have been increasingly expose to neoliberal discursive formations of self-interest, competiveness, and materialism (Coakley, 2011; Gill, 2008; Weidner, 2009). Correspondingly, nascent sociological research is consistently showing that although millennials do actively construct and negotiate their selfhoods around the competing discursive systems of culture and value available to them, very often these are, as Harvey et al. (2013: 9) argue, 'related to the circulation of global tropes of consumption and idealised neoliberal subjectivities' (see also Coakley, 2011; Lloyd, 2012; O'Flynn and Petersen, 2007).

But what exactly constitutes neoliberal subjectivity? To date, the sociological literature has offered rich explanatory accounts that describe various interlocked systemic imperatives and structural, discursive, policy, and civil society components that help engender the microlevel processes of neoliberal subjectification (Binkley, 2011; Gill, 2008; Hall and Rustin, 2015; Lloyd, 2012). However, propositions about: (1) the cognitive-affective mechanisms that explain how youth acquire and reproduce neoliberal ideology, or (2) the dispositions and behaviours that typify a neoliberal subject, remain vague (see e.g., Binkley, 2012; O'Flynn and Petersen, 2007; Weidner, 2009). Accordingly, a more in-depth conceptualization of these two psychosocial facets could help enhance and specify current understandings of how a neoliberal subject develops, thinks, feels, and acts. This could in turn advance empirical examinations of the emerging modes and societal consequences of neoliberal subjectification. Therefore, this article will provide an initial template for said conceptualization.

To do so, we first review and draw links between the shared, synergistic, and complementary theoretical tenets from the literature on neurocognitive development and social cognition in order to lay a computational-representational paradigm-based account of the processes of subjectification and social reproduction.1 We then review the literature on neoliberalism and neoliberal hegemony as these apply to the USA and the UK: the world harbingers and enforcers of neoliberal doctrine (Ellwood, 2011; Hall and Rustin, 2015; McGuigan, 2010). Finally, we synthesize the theoretical tenets and empirical findings discussed throughout the article within a modified version of the habitus formulation to sketch a testable cognitive-sociological model. This model provides a novel approach to help explain 
and empirically explore some of the distinct dispositional values, attitudes, and practices that youth raised in societies with institutionally and culturally prevalent neoliberal discursive formations may potentially develop and enact. This article can, therefore, be viewed as a response to ongoing calls for sociologists to engage with the cognitive sciences and clarify the psychological assumptions that are implicit in all sociological theories of culture and subjectivity (Cerulo, 2010; Srivastava and Banaji, 2011; Turner, 2007). Indeed, as Turner (2007: 359) argues, 'Minimizing the cognitive is a genuine alternative strategy to engaging with cognitive neuroscience, but only if we choose to push social theory to the far periphery of knowledge, into a ghetto of its own making.'

\section{Computational-Representational Theories Of Mind}

One of the leading paradigmatic positions in cognitive science is that the mind is a computational information-processing centre largely composed of evolutionarily endowed, hierarchically organized, and interconnected neural structures known as modules (Kumaran et al., 2009; Sperber and Hirschfeld, 2004). Modules are associated with and anchored across particular regions of the brain, and are hypothesized to be autonomous and informationally encapsulated devices with domain-specific functions (Bussey and Saksida, 2007). To wit, each module is theorised to possess a genetically determined syntactic algorithm with fixed parameters that is designed to only and mandatorily process certain sensory inputs to perform distinct cognitive tasks e.g., facial pattern recognition. Because of these computational properties, modules enable us to rapidly process, parse, remember, and react to the constant stream of sensory information that we encounter every day (Sperber and Hirschfeld, 2004). For the purposes of this article, a particularly important meta-module is termed the 'medial temporal lobe memory system' (Bussey and Saksida, 2007; Moscovitch, 2008). This module encompasses the hippocamupus and the parahippocampal, perirhinal, and entorhinal cortexes; houses multiple memory systems (e.g., working, episodic, semantic); and generates, stores, and interconnects smaller cognitive mechanisms known as schemas (Ghosh et al., 2014; Kumaran et al., 2009; van Kesteren et al., 2013).

Schemas (a.k.a. scripts, frames, gestalts, mental models), are generative and subjective knowledge structures, that are acquired and can be modified throughout life during exposure to and active interactions with the outside world or via thought processes. These structures can contain and process mental representations about the self, culture, abstract concepts, political ideologies, social norms, material entities, meanings of words, or experienced and imagined events etc. (Brod et al., 2015; Chiao et al., 2010). Despite the wide range of possible representations that schemas can pertain to, an individual schema's content consists of subject 
specific, context-sensitive, and hierarchically slotted information that is varyingly fragmented, shallow, and abridged. However, singular units can link to associative networks of interrelated schemas to form more cohesive, coherent, and sophisticated mental representations (Gilboa and Marlatte, 2017; Kumaran et al., 2009). Extensive neuroimaging and experimental psychology research indicates that schemas are encoded and cultivated in neural networks through anchoring and reconstructive processes (Chiao et al., 2010; van Kesteren et al., 2013), that are enabled and reinforced by neuronal dopaminergic substrates and reactions (Tse et al., 2011). Schema encoding and subsequent augmentation often occurs when incoming information is contextually, semantically, affectively, and/or conceptually congruent or otherwise associated with pre-existing superordinate schemas, which serve as informational attractor and scaffolding mechanisms (Gronau and Shachar, 2015; Robin and Moscovitch, 2014; Tse et al., 2011). For example, one's schema for doctors will likely be formed and syntactically defined upon first interacting with or learning about doctors. This coarse schema's base syntax can over time modify and expand itself in accordance with new information that corresponds to one's continued learning about and/or experiences with doctors or doctor-associated stimuli. These generative and combinatorial structural properties allow schemas to also connect and become co-activated with related schemas (Gilboa and Marlatte, 2017), which following the previous example, could include a nurse and/or health schema.

Schema encoding, modification, and networking are also essentially the processes underpinning attitudinal development. According to Bohner and Dickel (2011: 382) an attitude is a feeling or "evaluation of an object of thought [and attitude objects range] from the mundane to the abstract, including things, people, groups, and ideas". Attitudes can therefore be construed as affect-based schemas that contain and process affective meanings, and are tightly connected to or subsumed within related information-based schemas (Schroder and Thagard, 2013; Lodge and Taber, 2005). One's attitudes on welfare for example, will be necessarily tied to one's knowledge about welfare programmes and recipients. Additionally, depending on the context of their formation, valence strength, and activation frequency, attitudes can be ad hoc and relatively disposable, or durable and potentially life-long, as is often the case with e.g., political attitudes and stereotypes (Lieberman et al., 2003; Lodge and Taber, 2005). Moreover, weakly-held attitudes are highly amenable and negligibly affect judgement and behaviour. Conversely, strong attitudes are deep-seeded, resistant to change, and can powerfully affect motivation, judgment, behaviour, and the processing and 
development of information-based schemas (Kaplan et al., 2007; Lieberman et al., 2003; Schroder and Thagard, 2013).

Furthermore, schemas are consolidated and lie dormant in long-term memory waiting to be activated and retrieved in working memory. Evan's (2008) updated version of the dualprocessing system paradigm, states that this process occurs through the activation of system 1 -associated with implicit/tacit (i.e., reflexive, hot, automatic, nonconscious, offline) cognition- which delivers cued information to system 2- associated with explicit/agentic (i.e., reflective, cold, controlled, conscious, online) cognition. Hence, when cued, schemas can, depending on the context of their activation, manifest as conscious thoughts and guide deliberative actions. However, situational frequency and contiguity augment a schema's activation potential and behavioural automaticity. This means that chronically elicited schemas become more salient, excitable, and reactive over time such that when triggered by proximate situational cues, they can actuate nonconscious judgements, decisions, and behaviours (Baumeister and Bushman, 2008; Fiske and Taylor, 2013). These instances can be idiosyncratic and benign as can be the case for schemas that represent and guide one's morning routine practices or driving habits. Where this phenomenon becomes sociologically relevant, is in the case of schemas that contain intersubjectively shared sociocultural representations, because as will be discussed in the next section, their level of automaticity plays a critical role in subjectification and social reproduction (Brubaker et al., 2004; Kitayama and Park, 2010; Lodge and Taber, 2005). Yet, despite their power to propel individuals to nonconscious cognitive, affective and/or behavioural reactions, a schema's automatic function may in certain contexts and to varying degrees be superseded through concerted conscious effort (Bohner and Dickel, 2011; Lieberman et al., 2003). In particular, this can occur when individuals experience situations that run counter to their expectations, as these can induce an aversive arousal state (i.e., cognitive dissonance). This is because people have an innate inclination to maintain cognitive consonance (Lodge and Taber, 2005). Therefore, instances that activate internal inconsistency can force individuals to consciously engage with and then potentially alter their deep-seeded preconceptions and dispositional behaviours (Lieberman et al., 2003). However, this innate inclination can also lead individuals to reify their pre-existing schemas, and to unconsciously avoid information that may induce cognitive dissonance e.g., alternative political ideologies (Lodge and Taber, 2005).

To be certain, schema encoding, development, and processing are highly complex and dynamic phenomena that are dependent on various neurobiological chemical reactions, sensory motor systems, other cognitive mechanisms, innate psychological drives, and social 
propensities. These are far too numerous and complicated to go over in this parsimonious review, as are the theories and debates on how these all work and interact. However, the following summary statement and key points are quite empirically substantiated, and arguably accepted, shared, and/or implied by much of the neuroscience, cognitive psychology, and social cognition literatures. In sum, a schema's content, complexity, consolidation, saliency, behavioural automaticity, and connection to and co-activation with other schemas are largely determined by the frequency and socio-environmental and affective context in which it is accessed and utilised (Gilboa and Marlatte, 2017; Schroder and Thagard, 2013; van Kesteren et al., 2013). But, once encoded, schemas can:

- Store and organize memories, affects, knowledge and ideas; including their respective attributes and relationships to related schemas (Gronau and Shachar, 2015). This also includes information such as, motives, intentions, situations, and goals that "enable or inhibit certain behaviours, and causal sequence of events, as well as the specific behaviours themselves" (Baumeister and Bushman, 2008: 152).

- Enable the processing of affective, contextual, discursive, and semantic meanings and associations (Schroder and Thagard, 2013).

- Facilitate learning by enabling the rapid integration of new associations linked to incoming information (Brod et al., 2015).

- Function as heuristic mechanisms that enable quick judgments and decisions (Kumaran et al., 2009).

- Constitute an individual's mental representations of their self, and the intersubjectively shared cultural values, norms, attitudes and practices of their social groups (Chiao et al., 2010).

\section{Social Cognition, Subjectification, and Social Reproduction}

Possibly the majority of social cognition theories (SCTs) stem from the computational representational paradigm described above, and thus share the same informationprocessing understanding of cognition, and emply a schema-based or analagous conception of mental representations. However, these SCTs tend to focus more on explaining the ways that innate and acquired cognitive structures enable and are influenced by social interaction, learning, self-awareness, group dynamics, and culture (Bandura, 2001; Fiske and Taylor, 2013). There is naturally some disagreement between these various cousin theories (see e.g., Henrich and Boyd, 2002), but they for the most part have shared, complementary, and non-conflicting tenets that, when considered together, paint an account of subjectification and social reproduction, which goes as follows. 
Generally, SCTs begin with the premise that humans start developing their schema architectures during infancy by observing and mimicking the interpersonal practices and linguistic uses of their immediate family, and concurrently through ongoing interaction with people and social institutions (Bandura, 2001; Fiske and Taylor, 2013; Kitayama and Park, 2010). Social institutions are understood by SCTs as patterned distributions of behaviours and material resources that explicitly and implicitly superimpose upon individuals, specific and organized forms of social order and information (Hewer and Roberts, 2012; Ridgeway, 2006). These forms consist of cultural or political ideas, values, attitudes, histories, rules for acceptable behaviours, and practices, which usually function to perpetuate the status quo. Individuals, therefore, generate and form their subjectivities from active engagement with the social groups, institutional-discursive data, and cultural repositories available to them, in conjunction with repeated social interactions, rewards, sanctions, and negotiation of values with others. Thus, individuals can to a substantial degree constitute their subjectivities consciously because they are to a meaningful extent able to deliberatively take in, modify, and even dismiss the social information with which they are presented (Augoustinos et al., 2014). This agrees with Bandura's (2001: 1) argument that: 'Personal agency operates within a broad network of socio-structural influences. In these agentic transactions, people are producers as well as products of social systems.'

SCTs further suggest, however, that subjectification is also a considerably nonconscious process that functions through innate cognitive and psychological propensities and mechanisms. Of note, these include theory of mind; conformist social learning, attribution, and prestige biases; and mnemonic storage and elaboration devices, which enable individuals to mentalize the beliefs, desires, and perspectives of others, predict behaviours, intuit symbolic meanings, and anticipate and adapt to social situational expectations (Godfrey et al., 2017; Henrich and Boyd, 2002; Sperber and Hirschfeld, 2004). These also subliminally motivate individuals to want to identify with their respective social groups and culture, and to automatically attend to and construct mental representations of valuable, common, and widely shared social information (Kitayama and Park, 2010; Shimizu et al., 2017). Put simply, this all means that people are significantly predisposed and probabilistically more likely to detect, schematically internalize, and over time implicitly conform according to, social information that is: (1) repeatedly encountered and observed; (2) cognitively, affectively, and behaviourally congruent and contiguous; and (3) institutionally and culturally ubiquitous, valorized, and enforced (Augoustinos et al., 2014; Chiao et al., 2010; Lodge and Taber, 2005; Schroder and Thagard, 2013). This will vary by individual, but the more this predominant 
social information becomes internalized, reinforced, and suffused in people's formative schema networks, the more they can do the following:

- Form a major component of a person's self-identities (Augoustinos et al., 2014).

- Manifest as non-conscious cognitive, affective, and behavioural responses to lived relations and everyday institutional and cultural experiences and imperatives (Fiske and Taylor, 2013; Schro“der and Thagard, 2013; Shimizu et al., 2017).

- Lead individuals to naturalize, justify, legitimize, and conform to existing power relations and social inequalities (Augoustinos et al., 2014; Godfrey et al., 2017).

- Place durable neurocognitive parameters that can automatically block, bias, or distort the development of schemas for, or intake of, information corresponding to, opposing cultural and political ideas and practices (Chiao et al., 2010; Kaplan et al., 2007; Lodge and Taber, 2005).

- Organize and constrain a wide range of behaviours in a fashion 'consistent with the structural conditions framing the situation, even when that behaviour is not directly and materially constrained by those conditions' (Ridgeway, 2006: 9).

- Cause individuals to behaviourally and implicitly reproduce larger social structures and corresponding patterns of stratification and inequalities, even in situations 'in which the material constraints of the structure are insufficient to fully control individual behavior' (Ridgeway, 2006).

As this relates to social reproduction, SCTs posit that, in aggregate, these micro-level conditions can lead to macro-level sociocultural inertia (Henrich and Boyd, 2002; Ridgeway, 2006; Schroder and Thagard, 2013).

However, the generative and ultimately physically, biologically and socially constrained nature of human cognition means that an agent's encoding of even the most ideologically charged and institutionally disseminated social information is never an exact replication of the source data (Henrich and Boyd, 2002; Kitayama and Park, 2010). Our unique cognitive faculties, experiences, cultural geo-historic specificities, social positioning, and agency lead us to remember, process, recombine, and reproduce even dominant social information in fuzzy, incomplete, novel, or permutated ways that can mildly to significantly differ from individual to individual and from generation to generation. Furthermore, agents are often surrounded by both stable and more dynamic sources of social information, such as the mass media. This results in exposure to '[a] continuous and overwhelming flow of information, which either endorses or challenges the status quo' (Hewer and Roberts, 2012: 175). When looked at in tandem, all these inherent socio-cognitive dynamics can go some way towards 
explaining why we, for instance, are not institutional drones or carbon copies of our parents, and why societies are, to varying degrees, divergent and always changing. In other words, society does not indelibly stamp us, it instead provides us with foundational sociostructural algorithms that we are to some meaningful extent free to consciously modify and act on. Therefore, while relatively homeostatic, any given set of hegemonic institutional arrangements is never permanently fixed, as societies are inherently chaotic systems that are sensitive and continuously subject to spontaneous micro- and mesolevel agent-based modifications.

While the fused SCT account outlined above is somewhat similar to Talcott Parson's structural functionalism and Pierre Bourdieu's field theory, it differs from these classic sociological theories in the proceeding ways. First, unlike Parson's 'oversocialised man' or Bourdieu's 'habitus', this account is based on empirically tested conceptualizations of how people's neurocognitive architectures are developed and augmented through social interactions and both automatic and deliberative agency. Second, these architectures are composed of schemas that contain specific yet modifiable and context-sensitive content. This very much differs from Bourdieu's habitus construct, which effectively entails a content-free, general learning, relatively fixed, and reactive mechanism (Burawoy, 2012). Third, this account does not reduce subjectification or social reproduction to either socio-structural or cognitive-structural determinants, nor to conscious or nonconscious agency. Rather, it suggests that subjectification and social reproduction are the interrelated products of mutually reinforcing and dynamic interactions between biological-genetic, cognitive-affective, and institutional-discursive mechanisms and processes. These in turn enable and are enabled by volitional, dispositional, habitual, and spontaneous cognition and action. That said, later sections will demonstrate how this account can be further incorporated into a habitus reformulation to explain neoliberal subjectification and reproduction, but before doing so, we must first briefly discuss the literatures on neoliberalism.

\section{What is Neoliberalism?}

Neoliberalism refers to a political-economic paradigm based on an ideology that calls for the state implementation, facilitation, and enforcement of free-market economic systems and logic across national and global settings, and essentially across all forms of human organization and decision-making (Hall and Rustin, 2015; Peck and Tickell, 2002). Initially rising to prominence in the 1980 s in the UK and the US, neoliberalism has significantly shaped the $21^{\text {st }}$ century world order (Ellwood, 2011; Hall and Rustin, 2015; Plehwe et al., 2007). This paradigm has been influenced by several Western epistemic communities (e.g., Austrian and Frieburg Schools of Economics, the Mont Pelerin Society). Thus, various 
provincial strands of neoliberalism have sprouted e.g., Brazilian New Capitalism, German Ordoliberalism (Mirowski and Plehwe, 2009). This section, however, will only focus on outlining the key theoretical premises and policy prescriptions associated with the dominant UK and US strand.

The core of neoliberal theory and ideology as can be extracted from the works of seminal neoliberal theorists, starts with the assumption that human beings are predominantly possessive and instrumentally rational individuals. This indicates that while humans are capable of altruism, they will primarily and in the first instance behave in ways that are in accordance with their perceived self-interests (Friedman, 2002). From this essentialist conception of human nature follows the key normative position that despite their selfinterested predispositions, people's motivations and actions can and should be channelled for progressive socioeconomic development. However, this must only be done through politicaleconomic systems that engender relatively unfettered market forces, negative freedom, and the legal protection and appropriation of private capital (Hayek, 1994). Conversely, any attempts to harness the powers of the state to redistribute wealth and regulate markets for the public good, however benevolent and well intentioned, will have disastrous socio-economic outcomes. This is primarily because these objectives as traditionally advanced by state socialism and to a lesser extent by Keynesian forms of regulated capitalism, require excessive government economic intervention that distorts the natural pricing equilibrium mechanisms of supply and demand. Invariably, this results in the inefficient and wasteful allocation of finite resources and services (Friedman, 2002). Furthermore, these political-economic systems necessarily infringe on individuals' freedom to utilize their capital as they choose, which has the consequent effect of stifling the psychological incentives necessary for entrepreneurial innovation and economic growth. Coupled, these cumulative macro and micro effects inevitably generate high inflation, stagnant economies, and unproductive state dependent citizenries that in extreme cases can lead to despotism (Hayek, 1994).

As such, neoliberals advocate for monetary policies aimed at controlling inflation (Friedman, 1948). They postulate that in favouring monetary over fiscal policies, governments and central banks can help to increase and stabilize the real value (as opposed to nominal value) of financial assets. This puts more money into the hands of investors and entrepreneurs, and incentivizes them to make investments, which will lead to the creation of jobs and more efficient economic growth than can be achieved by means of government fiscal stimulus policies. Neoliberals further argue that in order to maintain international competitiveness and induce and accelerate economic growth, countries should 1) eliminate or drastically reduce 
trade barriers, corporate and income taxes, government public expenditures, and financial, labour and environmental regulations; 2) partially or fully privatize their natural resources, state enterprises, and services; and 3) focus on generating exports. In so doing, countries can gain from their comparative advantages in factor endowments, maintain market credibility, achieve fiscal solvency, and attract foreign direct investment.

However far from laisse-faire, neoliberals argue that a sound and prosperous economy necessitates state intervention to enforce contracts, protect property rights, and shore up markets in times of economic crisis (Friedman, 1948; Hayek, 1994). Thus, a minimal degree of funding for public services and private enterprises through fiscal revenues is consistent with neoliberal theory (e.g., negative income tax), provided that these are not "inimical to the initiative and functioning of the market" (Hartwell, 1995: 42). Nonetheless, neoliberals emphatically argue for the reduction of the welfare state by for example, making welfare benefits means-tested and temporary. They further propose that the primary function of welfare and education institutions should be to condition and train individuals to be selfreliant, entrepreneurial, and responsible decision makers. Moreover, public institutions should be made to compete for public funds against other public institutions and private profit and non-profit organisations. To facilitate this public institutional restructuring, neoliberals advocate for neo-managerial policies and corporate style accountability metrics and targets to help eliminate wastefulness, incentivize positive performances, measure outcomes, and maximise customer satisfaction (Chubb and Moe, 1990; Friedman, 2002). Neoliberals hypothesize that the sufficient enactment of their policy prescriptions will in the long-term create prosperous and dynamic, but stable and efficient national and international markets, in addition to the skilled, self-reliant, and flexible workers needed to maintain and compete in them (Friedman, 2002; Hartwell, 1995).

Geo-political specificities notwithstanding, since the governments of UK Prime Minister Thatcher and US President Reagan, the ideas and policies described above have been steadily implemented and advanced by interlocking groups of elite politicians, businesspeople, and intellectuals (Hall and Rustin, 2015; Mirowski and Plehwe, 2009; Plehwe et al., 2007). However, rather than ushering in more stable, beneficent, and equitable market societies than the post-WW2 Keynesian system, the neoliberal epoch has been marked by frequently recurring global financial crises, deep recessions, skyrocketing levels of socioeconomic inequality and environmental devastation (Ellwood, 2011; Hall and Rustin, 2015). Despite these consistent detrimental outcomes, neoliberal hegemony has not been supplanted, nor faced any serious unsettling as, to all extents and purposes, outbursts of public unrest and 
popular social movements have been relatively short-lived, subdued, or co-opted (Hall and Rustin, 2015; Reed, 2014).

\section{Neoliberal Hegemony}

It is not the intent here to imply that neoliberalism has become totalised, fixed, and uncontested. UK and US societies are like all others, marked by ideological ruptures and points of contestation generated by the constant dynamism of competing forces. Indeed, the neoliberal era has seen multitudes of resistance from the 1990s anti-globalization movements, to the 2010s Occupy encampments, to the recent rise of far-right nativist groups. Nevertheless, the fact does remain that major US and UK cultural and public institutions, such as mass media and education, have been considerably restructured by the types of policies described above, and turned into neoliberal market and ideological apparatuses that are significantly shaping millennials' selfhoods, social relations, and practices. ${ }^{2}$

For example, neoliberal policies such as the US's 1996 Telecommunications Act and the UK's Communication Act 2003 lifted restrictions on media ownership. Resultantly, print media and public broadcasts continue to be co-opted and stripped of substance by corporate conglomerates, or worse still, turned into manufacturers of ridiculous infotainment that celebrates the opulence of the rich and famous (Coleman, 2013; McChesney and Nichols, 2009), or vilifies the poor (Jensen and Tyler, 2015). In the UK for instance, there has been a recent influx of what is described as 'poverty porn' television shows (e.g., Benefits Street). These are documentary style programmes that depict welfare recipients as underserving and lazy scroungers. As Jensen (2014:2), argues, these shows "perform an ideological function [by generating] a new 'commonsense' around an unquestionable need for welfare reform". Neoliberal ideology can also be traced in the mainstream press' carefully spun and widely circulated sound-bites and opinion pieces that call for the reduction or elimination of welfare services, taxes, and union rights; the privatisation of public institutions and services; and the removal of economic, labour and environmental regulations (Jensen and Tyler, 2015; Plehwe et al., 2007). Notably, these messages are often developed by neoliberal think-tanks e.g., Adam Smith Institute, Heritage Foundation, Centre for Policy Studies, Institute of Economic Affairs (Plehwe et al., 2007). Moreover, this ideological saturation also includes an erosion of criticisms of corporate practices and neoliberal policies, along with a near constant vilification and misrepresentation of egalitarian ideals, unions, teachers, public schools, welfare recipients, redistributive policies, and market-critical political figures and organisations (Goldstein et al., 2011; Jensen, 2014). The few independent media that report non-elite interests, critical voices, and substantive policy debates are marginalized, constantly under- 
funded, and have very limited communicative reach (McChesney and Nichols, 2009). Although we can only speculate at this point and notwithstanding the contribution made by other possible causal factors, these media conditions and distributed discourses may to some extent be contributing to at least two related phenomena. The first is the UK public's decreasing support for paying more taxes to raise benefits for low-income and unemployed people, which has been declining for 30 years, and is noticeably lowest amongst millennials (Duffy et al., 2013). The second is the declining union membership in the UK and USA, which is also lowest amongst millennials (O’Connor, 2017).

Relatedly, popular culture now disseminates neoliberalism congruent discourses of materialism, competitiveness and self-interestedness that are more emphatic and prevalent than during pre-neoliberal times (Konrath et al., 2011; McGuigan, 2010; Uhls and Greenfield, 2011a). ${ }^{3}$ For example, a psycholinguistic study of the lyrics from the US's Hot 100 Billboard songs from 1980-2007, found that since 1980, the words 'I' and 'Me' have appeared more frequently in popular music lyrics, while prosocial words like 'We' and 'Us' have significantly dwindled (DeWall et al., 2011). The researchers also note that the rise in selfcentred and antisocial lyrics found in popular music correlates with several large-scale psychometric survey results indicating that American millennials are more narcissistic and self-interested than previous generations. Indeed, as Twenge and Campbell (2010) argue, the large majority of birth cohort studies have reported significant increases in individualistic and materialistic traits and decreases in civic interest in the American millennial generation. Related developmental psychology studies also show that the ubiquity and resulting exposure to materialistic media messages over the past 30 years, are correlated with rising levels of concerns over attaining wealth, fame, status, and material possessions amongst UK and US millennials (Easterbrook et al., 2014; Uhls and Greenfield, 2011b). Whereas other studies have speculated that this exposure may be contributing to post-1980 generational decreases in empathy, altruism, and communality (Konrath et al., 2011; Uhls and Greenfield, 2011a). Correspondingly, over the last two decades, UK and US commercial broadcasts have been dominated by reality television shows such as X-Factor, American Idol, and The Apprentice, which feature and promote cut-throat competition, narcissistic characters, rugged individualism, and materialism. In direct reference to these types of shows, Konrath et al., (2011: 189) note that, "overall, the agentic and narcissistic qualities found in modern media seem consistent with decreasing empathy".

With regards to education institutions, policies such as the US's 2009 Race To The Top Initiative and the UK's Education Act 2011, further instituted and extended the use of market- 
inspired accountability metrics to measure schools' competence and rank, and to in some instances determine their funding (Slater, 2015). As these metrics are primarily based on how well students perform on high-stakes standardised tests, teachers have been increasingly trained in and pressured to focus on, 'teaching to the test' classroom practices (Brown, 2010; Sloan, 2008). These practices are normally modelled on rote learning and behaviourist approaches, in that they are specifically designed to train students to attain an automated and uncritical acceptance of predetermined answers. Additionally, students are generally told that their test scores will determine whether and which university they can attend, which will in turn determine what types of jobs they can expect to attain (Patton, 2013). Current public education thus largely functions as another pivotal institutional environment where millennials are tacitly socialized to adopt consumerist, competitive, and instrumentalist mindsets and behaviours, which are concomitant with neoliberal ideology. Again, while we can only speculate at this point, these educational changes may help to partly explain why UK university enrolment in public service-orientated courses, such as education, which usually attracts students hoping to become teachers, has fallen from 198,120 in 2004/5 to 173,015 in 2013/14. Inversely, enrolment for business courses, which generally lure students hoping to get high-paying corporate jobs, has risen from 290,455 in 2003/4 to 336,600 in 2013/14 (Ramsden, 2015). These figures closely match longitudinal trends in the USA (NCES, 2016), and business is now by far the most popular university course in the UK and the USA.

All these institutional and discursive-formational changes have also coincided with a substantial weakening of labour unions and increase in the commodification of public spaces and leisure (Coakley, 2011; Peck and Tickell, 2002). This further diminishes millennials' probability of encountering counter-hegemonic ideas and practices, which then potentially negatively moderates their understanding of, interest in, or ability to imagine alternative cultural, institutional, and political-economic arrangements. The socio-structural and ideological convergence and synchronisation described in this section has thus resulted in a conjuncture where most US and UK millennials have no choice but to be repeatedly exposed to institutionally and culturally omnipresent neoliberal discursive formations. Hence, as suggested in recent ethnographic accounts, millennials are developing subjectivities that strongly reflect a neoliberal syntax or habitus as it were, which leads them to practices that contribute to the wider processes of neoliberal hegemony and reproduction (Coakley, 2011; Harvey et al., 2013; Lloyd, 2012). For example, with regards to his field study on young UK call-centre workers, Lloyd (2012:14) argues that: 
A significant reorientation of the labour market, coupled with an ideological swing towards consumerism, competition and social mobility, has fundamentally altered the outlook, identity and habitus of what was once called the working-class. The young men and women in my study are a generation of individuals with no link to previous forms of working-class sociality, culture and identity. Instead they embody the key [neoliberal] cultural and economic themes of our time.

\section{Constituting A Neoliberal Habitus: A Working Model}

The habitus construct has been routinely and widely criticised for being loosely defined, unfalsifiable, and psychologically inadequate (Burawoy, 2012). ${ }^{4}$ Van dijk (1998), for example, argues that the habitus offers a less explicit notion of a system of mental social representations, and its conception of 'disposition' is premised on circular reasoning because it "defines cognitive structures in terms of their output (such as social practices) which precisely need to be explained in terms of other cognitive representations." (pg. 47). Despite these limitations, the habitus is a useful and rather pliant conceptual device that can be retrofitted with the empirically substantiated theoretical insights from the literatures discussed throughout this article to create a provisional ideal-type neoliberal habitus characterization. Before doing so, three reiterations must be made.

First, the conception of habitus offered here is defined as an agent's acquired sum of related, content-specific, and contextually activated schemas that form a particular major component of the self, such as a role, identity, or sociocultural framework. These schemas can prompt nonconscious cognitive, affective, and behavioural reactions, but also fuel and can be modified and acted on via agential deliberation. Moreover, a subject can develop multiple habituses that can differ in magnitude, weight, consolidation, and automaticity, as well as overlap, be separate from, or conflict with one another. Hence, this habitus conception accounts for the capacity of subjects to develop multiple roles, identities, and cultural and political scripts, and to hold and act on these even when they contain inconsistent elements.

Second, schema encoding and development are the products of dynamic experiential, social interactional, and accretionary cognitive processes. To wit, schemas are first encoded from exposure to and interaction with novel environmental stimuli e.g., words, images, social practices etc., as these instances can spontaneously generate within a subject an initial affective, lexical, and semantic mental impression i.e., a contextually and conceptually specific referent (Gronau and Shachar, 2015; Kitayama and Park, 2010). This base syntax can be enhanced through subsequent exposure to contextual cues and information revealed during 
interaction (Brubaker et al., 2004). Furthermore, increasing a schema's activation potentiates its power to guide perception and recall, generate expectations and inferences, filter out competing or dissonant information, cue related schemas, and orient actions (Brod et al., 2015; Brubaker et al., 2004; Lodge and Taber, 2005). When a given schema exceeds an activation threshold, it can then become automatically expressed, reinforced, and/or coactivated with related schemas during exposure to relevant stimuli (Kitayama and Park, 2010; Shimizu et al., 2017). Thus an encoded schema's dispositional strength, salience, weight, and network size are primarily determined by activation frequency- which is, in turn, dependent on:

Proximate, situationally specific cues and triggers, not directly on large-scale structural or cultural contexts, though structural and cultural changes can affect the distribution of such proximate cues and thereby the probabilities of activation of schemas (Brubaker et al., 2004: 42).

Third and correspondingly, high levels of cultural-political discursive, material, and functional convergence and synchronicity between major social institutions increase the distribution, commonality, observability, and enforcement of dominant forms of social information. Individuals growing up and interacting in these auto-correlated environments are more likely to have the representations and affective meanings of said information encoded in their formative sociocultural schemas (Henrich, and Boyd, 2002). In these conditions, subjects are also more likely to have these schemas be chronically activated, which can over time, lead them to as Schroder and Thagard, (2013:256) argue: "implicitly reproduce the social order of their culture" (Kitayama and Park, 2010; Shimizu et al., 2017). Brubaker et al., (2004) note that in this respect, sociocultural schemas complement and can be used to re-specify the original habitus concept, as they effectively refer to 1) widely shared mental representations of distinct sociocultural dispositions and practices which orient corresponding outputs; and 2) some of the key cognitive-affective mechanisms through which subjects acquire and reproduce a culture and political-economic ideology (Henrich, and Boyd, 2002; Kitayama and Park, 2010; Schroder and Thagard, 2013).

An individual's sociocultural habitus can, therefore, be thought of as a network of associated and contiguous sociocultural schemas that correspond to the specific discourses and practices of whatever dominant institutions and culture they are subjected to during their ontogenetic development. Moreover, when instantiated, i.e., activated by relevant stimuli, this habitus orients contextually corresponding practices that maintain and reproduce existing societal arrangements. Additionally, individuals raised in institutional and cultural settings 
that regularly promote a hegemonic ideology, and where exposure to counter-hegemonic discursive formations is limited, should on average develop and display more ideologically consistent-harmonious sociocultural habituses. Consistent with this reasoning, the content and development of a neoliberal habitus are thus largely a function of recurring engagement with institutionally and culturally omnipresent and enforced neoliberal discursive formations (i.e. neoliberal ideologically inflected or congruent forms of social information). We will now elaborate on how this particular sociocultural habitus can theoretically manifest in UK and US millennials, but we must first emphasize that this probabilistic formulation does not preclude or negate the possibility that millennials can and may be developing alternative or inharmonious habituses.

Developmental research has consistently found that youth are highly susceptible to peer and media influences, receptive to popularly held beliefs and attitudes, and more likely to implicitly and explicitly conform to and enforce commonly observed norms (Easterbrook et al., 2014; Godfrey et al., 2017). Correspondingly, contemporary UK and US youth are frequently presented with social information that reflects or is congruent with neoliberal ideology. This includes beliefs and values such as capitalism rewards hard work, education leads to high paying jobs, wealth and material possessions increase happiness, welfare is too generous, unions are bad, etc. These are of course simplistic metonyms for complicated social information that is presented, framed, and enacted in myriad fashions through various mediums and complex forms of social interaction. But they more or less capture the gist of what, as i briefly outlined in the previous section, UK and US millennials are frequently presented by media, schools, and society at large (Coakley; 2011; Goldstein et al., 2011; Jensen, 2014; Patton, 2013; Uhls and Greenfield, 2011a). Furthermore, media and schools are the institutions where most youth possibly spend the majority of their waking hours interacting with others and learning about culture and politics. This indicates that said youths' formative sociocultural schemas are regularly instantiated. During instantiation, incoming information is normally assimilated or accommodated into relevant pre-existing schemas. Instantiation thus facilitates encoding, and every instantiation can gradually augment a schema's structure. Several factors play a role in this, but information/stimuli that are thematically, conceptually, or otherwise related or repeatedly presented together (e.g. media discourses of capitalism, wealth, material possessions), are easier to process and more likely to become encoded (Gilboa and Marlatte, 2017).

Moreover, there is a high degree of conceptual, affective, and behavioural congruity between materialism, individualism, anti-unionism, and anti-welfare discursive formations, 
for example, they all promote self-interested thoughts, attitudes, and practices. These discursive formations are also regularly proximately presented in mass media. For example, UK popular tabloids like the Sun and Daily Mail often feature stories about welfare 'cheats' or 'greedy' unions surrounded by adverts for consumer products. It stands to reason then that chronic engagement with these neoliberal congruent discursive formations will to some degree make an impression on young people's neurocognitive architectures. If sufficiently strong, this impression can in relevant social contexts, organize and orient their behaviours. However, while it can be assumed that this impression will vary by individual, neuroschematic content cannot be directly observed. Therefore, to test these assertions, semantic and lexical conceptualizations of sociocultural schemas and practices that reflect typical neoliberal discursive formations must instead be developed to serve as plausible observable indicators. Based on everything discussed thus far, such proxy sociocultural schemas and practices that can reasonably be said to correspond to a neoliberal habitus, may in part entail those listed in Table 1. These are admittedly crude and arbitrarily worded conceptualizations, and some of the listed schemas and practices may need to be discarded or modified and others added, following empirical scrutiny. Nonetheless, while this typological composite sacrifices the subtleties and complexities of social reality and of plausible neuroschematic representations, it can a' la Weberian tradition, be used to explore and compare how, why, and the degree to and context in which real cases diverge from or converge with it. 


\begin{tabular}{|c|c|}
\hline \multicolumn{2}{|c|}{ Neoliberal Habitus } \\
\hline Sociocultural Schemas & Corresponding Social Practices \\
\hline $\begin{array}{l}\text { - Financial wealth is a mark of success. } \\
\text { - Owning more and expensive material } \\
\text { possessions increases happiness. } \\
\text { - Individuals should be self-reliant, self- } \\
\text { concerned, and entrepreneurial. }\end{array}$ & $\begin{array}{l}\text { - Continuous purchasing of or efforts to purchase } \\
\text { corporate products, even in instances when it is } \\
\text { known that they stem from exploitative } \\
\text { conditions and/or have negative environmental } \\
\text { impacts. } \\
\text { - Idolising wealthy celebrities and/or } \\
\text { entrepreneurs. } \\
\text { - Refusal to participate in consumer boycotts if the } \\
\text { corresponding product or service is cheaper than } \\
\text { alternatives. }\end{array}$ \\
\hline $\begin{array}{l}\text { - Socioeconomic status is principally } \\
\text { determined by personal effort and } \\
\text { choices. } \\
\text { - Schools should primarily focus on jobs } \\
\text { training. } \\
\text { - The best careers are those that pay the } \\
\text { highest salaries. } \\
\text { - People are paid fairly according to their } \\
\text { effort and skills. }\end{array}$ & $\begin{array}{l}\text { - Instrumentalist selection of schools, degrees, } \\
\text { and careers. } \\
\text { - Consumerist engagement with education. } \\
\text { - Self-branding, networking, and impression } \\
\text { management. } \\
\text { - Conspicuous consumption. }\end{array}$ \\
\hline $\begin{array}{l}\text { - Competition and hard work ensures } \\
\text { meritocratic outcomes. } \\
\text { - Public institutions should be run like } \\
\text { businesses. } \\
\text { - Capitalism is the only viable economic } \\
\text { system. } \\
\text { - Welfare recipients and impoverished } \\
\text { peoples are mostly lazy and unambitious. } \\
\text { - Government social programs are overly } \\
\text { generous and economically burdensome. } \\
\text { Increasing taxes to fund social services is } \\
\text { unfair to individuals that work hard. } \\
\text { Unions increase prices, create job losses, } \\
\text { and prevent the firing of incompetent } \\
\text { workers. }\end{array}$ & $\begin{array}{l}\text { - Rejecting socialist/communitarian ideas and } \\
\text { policies. } \\
\text { - Supporting welfare reforms that limit the } \\
\text { timeframe and amount of benefits that can be } \\
\text { claimed. } \\
\text { - Supporting (e.g., voting for) politicians that } \\
\text { prioritise market/economic growth over social, } \\
\text { labour, and environmental protections. } \\
\text { - Supporting politicians that promise cuts to taxes } \\
\text { and funding for social programmes. } \\
\text { - Refusal to join a union, participate in strikes, or } \\
\text { honour picket lines. } \\
\text { Minimal contributions to charities and } \\
\text { environmental conservation. }\end{array}$ \\
\hline
\end{tabular}

It must be stressed that the model described above, consisting of both the neoliberal habitus conceptualisation and typological composite is like most initial theoretical 
abstractions, a messy first approximation in need of conceptual refinement. This includes an account of how other subjectivity-habitus types (e.g., gender, class) fit or differ from it, which cannot be sufficiently discussed here. That said, the listed sociocultural schemas and practices are conceptually consistent with the literature on neoliberal subjectivity and hegemony (Coakley, 2011; Hall and Rustin, 2015; Lloyd, 2012; O’Flynn and Petersen, 2007; Weidner, 2009). They are also largely based on the hitherto unconnected empirical evidence showing some of the ways that UK and US millennials' educational, political, and social-psychological values, attitudes, and practices resonate with neoliberal ideology, as described in the previous section. Hence, in pulling these otherwise disparate bits of evidence together and adding a situationally corresponding behavioural component, this model can be used to explore and test the extent to which UK and US millennials are developing and enacting a neoliberal habitus.

\section{Falsification: Some Suggestions}

Although this is not the space to outline a detailed research programme, the model offers a reference point for observable value, attitudinal and behavioural outputs, and proposes that the strength and development of these outputs are, in large part, determined by frequent engagement with culturally and institutionally ubiquitous, promoted and enforced neoliberal congruent discursive formations. Thus, the neoliberal habitus composite for instance, can be utilised to form qualitative interview schedules and guide ethnographic observations in schools, youth centres, and social media sites. In brief, this qualitative methodology would entail observing and documenting the extent and real-life instances in which youth consciously or implicitly articulate, reify, contest, or reject, as well as are presented and socially pressured to conform to, values, attitudes, and practices akin to those listed in the composite.

However, an easier and more concrete way to test the model, is to use the typological composite to develop psychometric survey scales, and/or a variation of the Implicit Association Test -which is used to measure individuals' non-conscious attitudinal associations, valence, and biases (see e.g., Srivastavaa and Banaji, 2011). These can be coupled with other survey or experimental instruments that gauge contextual behavioural responses, such as vignettes that describe neoliberal welfare and economic policies, and measure participants' support for their enactment. Additionally, gauging exposure and pressure to conform to neoliberal congruent discursive formations can for starters be done by measuring the frequency with which the following occur:

1. Participants consume materialistic and politically mainstream media content.

2. Participants are complimented by their peers for purchasing branded consumer 
products, and ridiculed for having outdated products.

3. Participants are encouraged by their parents, peers, teachers, or media to select careers primarily on salary concerns, and discouraged from aspiring to typically lesser-paid socially minded careers (e.g., social worker, teacher).

4. Participants are encouraged by their parents, peers, teachers, or media to vote for mainstream pro-market party candidates, and discouraged to vote for or engage with market-critical politicians, parties, and ideas.

This quantitative methodology can then be used to test two preliminary hypotheses:

H1: The schemas in the model are hypothesized to be contagious, such that the activation of one should theoretically prime the activation of the others. These schemas are therefore predicted to be significantly and positively correlated with each other and with the featured social practices.

$\mathrm{H} 2$ : Increase in the frequencies of cases $1,2,3$, or 4, will positively moderate the holding and enactment of the values, attitudes, and practices listed in the model.

The statistical significance of $\mathrm{H} 1$ and $\mathrm{H} 2$ will likely be affected by relevant demographic factors (e.g., age, class, gender, ethnicity, education) and psychographic factors (e.g., formal political socialization, social dominance orientation). The mediating and moderating effects of these factors should thus be examined. Lastly, whichever methods are used to test this model, its testing can help: (1) to identify some of the necessary and sufficient conditions and factors that generate, potentiate, or hinder the processes of neoliberal subjectivity-habitus formation; and (2) to inform understandings of the societal consequences of these processes; the sociological research for both of which is currently limited.

\section{Conclusion}

When considered together, growing evidence from parallel bodies of sociological and psychological research suggests that the ongoing neoliberal subjectification of UK and US millennials is associated with various adverse social and psychological effects (Easterbrook et al., 2014; Lloyd, 2012; Uhls and Greenfield, 2011a). This process may also be generating indifference towards or directly feeding the growing levels of socioeconomic disparity and environmental degradation induced by the past 30 years of neoliberalism. It is this article's contention that to better understand and investigate all these interrelated phenomena, current sociological accounts can benefit from a more in-depth conceptualization and formalization of the specific subjectivity habitus that can develop from extended interaction with institutionally and culturally prevalent neoliberal discursive formations. To this end, a cognitive-sociological model is proposed to explain and examine the ways in which 
sociocultural cognitive-affective mechanisms enable, constrain, and mediate individual thought and action, and the ways these then help to sustain the current neoliberal order. While this model in no way captures the complexity of these dynamics, it incorporates rich theoretical insights from the cognitive sciences, and offers a novel framework for how to more robustly conceptualize and empirically explore them. Finally, although this model is situated within a US and UK context, it offers a set of falsifiable propositions and methodological recommendations that can be applied and tested in countries with advanced or burgeoning neoliberalization.

\section{Notes:}

1. Subjectification is defined here as the process of becoming a subject i.e., of forming a selfidentity or multiple identities. Social reproduction refers to "all the mechanisms, processes, and practices by which multiple social hierarchies, divisions and relations of wealth, power, and influence are sustained and re-created over time" (Gewirtz and Cribb, 2009: 86).

2. Some of the examples that I provide to empirically support this claim have been plucked from nationally representative datasets and extensive developmental psychology research, but are conceptually consistent with the literature on neoliberal hegemony and subjectification. Thus, the account and examples that I provide in this article are not based on the research or meant to bolster popular accounts that depict millennials as being self-entitled and unwilling to commit to employment (Allen et al., 2015). Such dispositions may indeed be in some way a product of neoliberal policy and structural changes, but there is currently little, and even then conflicting, empirical evidence to support the notion that millennials exhibit these dispositions more so than previous birth cohorts (Fogarty et al., 2017). Moreover, because of this very limited empirical grounding, the analyses and model described in this article does not account for this infant research.

3. Self-interestedness, competitiveness, materialism, and rationalism are also core to liberal precursors and thus not unique to neoliberalism. The argument here is simply that these traits are considerably more amplified and promoted in neoliberal societies.

4. The original habitus construct is defined by Bourdieu (1977: 5) as a: "system of lasting, transposable dispositions which, integrating past experiences, functions at every moment as a matrix of perceptions, appreciations, and actions and makes possible the achievement of infinitely diversified tasks, thanks to analogical transfers of schemes permitting the solution of similarly shaped problems".

\section{Acknowledgements:}

I would like to thank Professor Meg Maguire for her invaluable help with this article. 


\section{References:}

Allen R S, Allen D E, Karl K, and White C S (2015) Are millennials really an entitled generation? An investigation into generational equity sensitivity differences. The Journal of Business Diversity, 15(2): 14-26.

Augoustinos M, Walker I and Donaghue N. (2014) Social Cognition: An Integrated Introduction. Los Angeles: Sage.

Bandura A (2001) Social cognitive theory: An agentic perspective. Annual Review of Psychology 52(1): 1-26.

Baumeister R F, and Bushman B J (2008) Social Psychology and Human Nature. Toronto: Nelson Learning.

Binkley S (2011) Happiness, positive psychology and the program of neoliberal governmentality. Subjectivity 4(4): 371-394.

Bohner G and Dickel N (2011) Attitudes and attitude change. Annual Review of Psychology 62: 391-417.

Bourdieu P (1977) Outline of a Theory of Practice. Cambridge: Cambridge University Press.

Brod G, Lindenberger U, Werkle-Bergner M and Shing Y L (2015) Differences in the neural signature of remembering schema-congruent and schema incongruent events. Neuroimage 117: 358-366.

Brown C P (2010) Children of reform: The impact of high-stakes education reform on preservice teachers. Journal of Teacher Education 61(5): 477-491.

Brubaker R, Loveman M and Stamatov P (2004) Ethnicity as cognition. Theory and Society 33(1): 31-64.

Burawoy M (2012) The roots of domination: Beyond Bourdieu and Gramsci. Sociology 46(2): 187-206.

Bussey T J and Saksida L M (2007) Memory, perception, and the ventral visual perirhinal hippocampal stream: Thinking outside of the boxes. Hippocampus 17(9): 989-908.

Cerulo K A (2010) Mining the intersections of cognitive sociology and neuroscience. Poetics 38(2): 115-132.

Chiao J Y, Harada T, Komeda H, Li Z, Mano Y, Saito D, Parrish T B, Sadato N and Iidaka T (2010) Dynamic cultural influences on neural representations of the self. Journal of Cognitive Neuroscience 22(1): 1-11.

Chubb J E and Moe T M (1990) Politics, Markets, and America's Schools. Washington DC: The Brookings Institution. 
Coakley J (2011) Ideology doesn't just happen: Sports and neoliberalism. Journal of ALESDE 1(1): 67-84.

Coleman S (2013) Debate on television the spectacle of deliberation. Television and New Media 14(1): 20-30.

DeWall C N, Pond Jr R S, Campbell W K and Twenge J M (2011) 'Tuning in to psychological change: Linguistic markers of psychological traits and emotions over time in popular US song lyrics'. Psychology of Aesthetics, Creativity, and the Arts 5(3): 200207.

Duffy B, Hall S, O'Leary D and Pope S (2013) Generation Strains. A Demos and Ipsos MORI Report on Changing Attitudes to Welfare. London: Demos.

Easterbrook M J, Wright M L, Dittmar H and Banerjee R (2014) Consumer culture ideals, extrinsic motivations, and well-being in children. European Journal of Social Psychology 44(4): 349-359.

Ellwood W (2011) No-nonsense guide to globalization. New York: New Internationalist/Verso.

Evans J S B (2008) Dual-processing accounts of reasoning, judgment, and social cognition. Annual Review of Psychology 59: 255-278.

Fiske S T and Taylor S E (2013) Social cognition: From brains to culture. London: Sage.

Fogarty T J, Reinstein A and Heath R S (2017) Are Today's Young Accountants Different? An Intergenerational Comparison of Three Psychological Attributes. Accounting Horizons 31(2): 83-104.

Friedman M (1948) A monetary and fiscal framework for economic stability. The American Economic Review 38(3): 245-264.

Friedman M (2002) Capitalism and Freedom. Chicago: University of Chicago Press.

Gewirtz S and Cribb A (2009) Understanding education: A sociological perspective. Cambridge: Polity Press.

Gilboa A and Marlatte H (2017) Neurobiology of Schemas and Schema-Mediated Memory. Trends in Cognitive Sciences 21(8): 618-631.

Gill R (2008) Culture and Subjectivity in Neoliberal and postfeminist times. Subjectivity 25 (1): 432-445.

Ghosh V E, Moscovitch M, Colella B M and Gilboa A (2014) Schema representation in patients with ventromedial PFC lesions. The Journal of Neuroscience 34(36): 12057 12070. 
Godfrey E B, Santos C E and Burson E (2017) For Better or Worse? System Justifying Beliefs in Sixth-Grade Predict Trajectories of Self-Esteem and Behavior Across Early Adolescence. Child Development. Epub ahead of print 19 June 2017. DOI:10.1111/cdev.12854

Goldstein R, Macrine S and Chesky N (2011) Welcome to the" New Normal": The News Media and Neoliberal Reforming Education. Journal of Inquiry and Action in Education 4(6): 112-132.

Gronau N and Shachar M (2015) Contextual consistency facilitates long-term memory of perceptual detail in barely seen images. Journal of Experimental Psychology: Human Perception and Performance 41(4): 1095-1111.

Hall S and Rustin M (eds.) (2015) After Neoliberalism?: The Kilburn Manifesto. London: Lawrence and Wishart Limited.

Hartwell M (1995) A History of the Mont Pelerin Society. Liberty Fund Inc.

Harvey L, Ringrose J and Gill R (2013) Swagger, Ratings and Masculinity: Theorising the Circulation of Social and Cultural Value in Teenage Boys' Digital Peer Networks. Sociological Research Online 18(4): 9.

Hayek F (1994) The Road to Serfdom. Chicago: University of Chicago Press.

Henrich J and Boyd R (2002) On modeling cognition and culture. Journal of Cognition and Culture 2(2): 87-112.

Hewer C J and Roberts R (2012) History, culture and cognition: Towards a dynamic model of social memory. Culture and Psychology 18(2): 167-183.

Jensen T (2014) Welfare commonsense, poverty porn and doxosophy. Sociological Research Online 19(3): 3.

Jensen T and Tyler I (2015) 'Benefits broods': The cultural and political crafting of anti welfare commonsense. Critical Social Policy 35(4): 470-491.

Kaplan J T, Freedman J and Iacoboni M (2007) Us versus them: Political attitudes and party affiliation influence neural response to faces of presidential candidates. Neuropsychologia 45(1): 55-64.

Kitayama S and Park J (2010) Cultural neuroscience of the self: understanding the social grounding of the brain. Social Cognitive and Affective Neuroscience 5: 111-129.

Konrath S H, O'Brien E H and Hsing C (2011) Changes in dispositional empathy in American college students over time: A meta-analysis. Personality and Social Psychology Review 15(2): 180-198. 
Kumaran D, Summerfield J J, Hassabis D and Maguire E A (2009) Tracking the emergence of conceptual knowledge during human decision making. Neuron 63(6): 889-901.

Lieberman D M, Schreiber D and Ochsner N K (2003) Is Political Cognition Like Riding a Bicycle? How Cognitive Neuroscience Can Inform Research on Political Thinking. Political Psychology 24(4): 681-704.

Lloyd A (2012) Working to live, not living to work: Work, leisure and youth identity among call centre workers in North East England, Current Sociology 60(5): 619-635.

Lodge, M., and Taber, C. S. (2005). The automaticity of affect for political leaders, groups, and issues: An experimental test of the hot cognition hypothesis. Political Psychology 26(3): 455-482.

McChesney M R and Nichols J (2009) The Death and Life of American Journalism: The Media Revolution That Will Begin the World Again. New York: Nation Books.

McGuigan J (2010) Cool Capitalism. London: Pluto Press.

Mirowski P and Plehwe D (eds.) (2009). The Road from Mont Pelerin: The Making of The Neoliberal Thought Collective. Harvard University Press.

Moscovitch M (2008) The hippocampus as a stupid, domain specific module: Implications for theories of recent and remote memory, and of imagination. Canadian Journal of Experimental Psychology 62(1): 62-79.

National Center for Education Statistics (2016) Digest of Educational Statistics. Available at: https://nces.ed.gov/programs/digest/d16/tables/dt16_322.10.asp?current=yes

O’Connor S (2017) Trade unions strive to stay relevant by wooing the young. The Financial Times. September 18.

O'Flynn G and Petersen E B (2007) The 'good life' and the 'rich portfolio': Young women, schooling and neoliberal subjectification. British Journal of Sociology of Education 28(4): 459-472.

Patton G (2013) Children to be told which GCSEs lead to best-paid jobs. The Telegraph, September 01.

Peck J and Tickell A (2002). Neoliberalizing space. Antipode 34(3): 380-404.

Plehwe D, Walpen B J and Neunhöffer G (eds.). (2007) Neoliberal Hegemony: A Global Critique. New York: Routledge.

Ramsden B (2015) Patterns of Higher Education Institutions in the UK. Universities UK.

Reed A (2014) 'Nothing Left: The Long Slow Surrender of American Liberals'. Harpers. Available at http://harpers.org/archive/2014/03/nothing-left-2/

Ridgeway L C (2006) Linking Social Structure and Interpersonal Behavior: A Theoretical 
Perspective on Cultural Schemas and Social Relations. Social Psychology Quarterly 69(5): 5-16.

Robin J and Moscovitch M (2014) The effects of spatial contextual familiarity on remembered scenes, episodic memories, and imagined future events. Journal of Experimental Psychology: Learning, Memory, and Cognition 40(2): 459-475.

Schröder T and Thagard P (2013) The affective meanings of automatic social behaviors: Three mechanisms that explain priming. Psychological Review 120(1): 255-280.

Shimizu Y, Lee H and Uleman J S (2017) Culture as automatic processes for making meaning: Spontaneous trait inferences. Journal of Experimental Social Psychology 69: $79-85$.

Srivastava S B and Banaji M R (2011) Culture, cognition, and collaborative networks in organizations. American Sociological Review 76(2): 207-233.

Slater G B (2015) Education as recovery: neoliberalism, school reform, and the politics of crisis. Journal of Education Policy 30(1): 1-20.

Sloan K (2008) The expanding educational services sector: neoliberalism and the corporatization of curriculum at the local level in the US. Journal of Curriculum Studies 40(5): 555-578.

Sperber D and Hirschfeld A L (2004). The cognitive foundations of cultural stability and diversity. Cognitive Sciences 9(1): 40-47.

Tse D, Takeuchi T, Kakeyama M, Kajii Y, Okuno H, Tohyama C, Bito H and Morris R G (2011) Schema dependent gene activation and memory encoding in neocortex. Science 333(6044): 891-895.

Turner S (2007) Social theory as a cognitive neuroscience. European Journal of Social Theory 10(3): 357-374.

Twenge J M and Campbell W K (2010) Birth cohort differences in the monitoring the future dataset and elsewhere: Further evidence for Generation Me-Commentary on Trzesniewski and Donnellan (2010). Perspectives On Psychological Science 5(1): 81-88.

Uhls Y and Greenfield P (2011a) The Rise of Fame: An Historical Content Analysis. Cyberpsychology: Journal of Psychosocial Research on Cyberspace 5(1): article 1. Available at https://journals.muni.cz/cyberpsychology/article/view/4243

Uhls Y and Greenfield P (2011b) The Value of Fame: Preadolescent Perceptions of Popular Media and Their Relationship to Future Aspirations. Developmental Psychology 48(2): 315-326.

Van Dijk T A. (1998) Ideology: A multidisciplinary approach. London: Sage. 
Van Kesteren M T, Beul S F, Takashima A, Henson R N, Ruiter D J and Fernández G (2013) Differential roles for medial prefrontal and medial temporal cortices in schema dependent encoding: From congruent to incongruent. Neuropsychologia 51(12): 23522359.

Van Kesteren M T, Ruiter J D, Fernandez G and Henson N R (2012) How Schema and Novelty Augment Memory Formation. Trends In Neuroscience 35(4): 211-210.

Weidner J R (2009) Governmentality, capitalism, and subjectivity. Global Society 23(4): 387 411. 